\title{
HUMAN-ELEPHANT CONFLICT IN PUMAT NATIONAL PARK REGION, NGHE AN PROVINCE: CURRENT STATUS AND IMPACT ON THE CONSERVATION ATITUDE OF LOCAL RESIDENTS
}

\author{
Nguyen Xuan Dang ${ }^{1, *}$, Nguyen Xuan Nghia $^{1},{ }^{1}$ guyen Tien Dat ${ }^{2}$, Nguyen Thanh Luong ${ }^{1}$ \\ ${ }^{1}$ Institute of Ecology and Biological Resources, VAST, Vietnam \\ ${ }^{2}$ Centre for Resources, Environment and Climate change, VUSTA, Ha Noi, Vietnam
}

Received 8 June 2020, accepted 30 September 2020

\begin{abstract}
$\mathrm{Pu}$ Mat National Park (NP) region is designated by the Government of Vietnam as a priory area for conservation of the Asian elephant. Out of three elephant groups currently inhabited Pu Mat NP region, only the group in Anh Son District (Anh Son elephant group) causes severe humanelephant conflict (HEC) with significant economic damage for local villagers and rubber farms, human casualties, and induced psychological pressure for local residents. Because of the HEC, support for the elephant conservation of local residents was significantly reduced and the retaliatory killing of an elephant happened in 2011.This study assessed the HEC status in Anh Son District and identified the main causes of HEC here.
\end{abstract}

Keywords:Elephas maximus, biodiversity conservation, endangered species, human-elephant conflict, Pu Mat National Park.

Citation: Nguyen Xuan Dang, Nguyen Xuan Nghia, Nguyen Tien Dat, Nguyen Thanh Luong, 2020. Human-elephant conflict in Pu Mat National Park region, Nghe An Province: current status and impact on the conservation atitude of local residents. Academia Journal of Biology, 42(4): 41-49. https://doi.org/10.15625/2615-9023/v42n4.15122

*Corresponding author email: dangiebr@gmail.com

C2020 Vietnam Academy of Science and Technology (VAST) 


\section{INTRODUCTION}

The Asian elephant, Elephas maximus, is currently distributed in 13 Asian countries with an estimation population of ca. 40,000 individuals throughout its ranges. This species is critically threatened by illegal hunting, trade, habitat loss/degradation and ever-increasing HEC (IEF 2017). In many countries, HEC causes significant economic damage and psychological pressure for local communities. Consequently, the number of retaliatory killings of elephants has been ever increasing. Thus, resolution of HEC is a major concern and a high priority for conservationof elephants in their range countries (Fernando et al., 2008; WWF, 2015; Desai et al., 2015; NPPC et al., 2016; Phub. et al., 2017).

In Vietnam, a native country of Asian elephants, the elephant population has been critically decreased to only 100-130 individuals in the wild (Nguyen Xuan Dang, 2015; Vietnam Forestry Department, 2018). They live in very small (mostly below 5 individuals) and isolated groups, while threats to their survival (illegal hunting and trade, habitat loss, degradation, increase of HEC,...) are widespread. In order to save the remaining Asian elephants, the Government of Vietnam has designated 3 priority areas for elephant conservation, one of which is the Pu Mat NP region (Decision No. 763/QD-Ttg, dated 21 May 2013 of Prime-Minister).

$\mathrm{Pu}$ Mat NP region, located in the Southwest of Nghe An Province, on the border with Laos, covers administrative territories of Anh Son, Con Cuong, Tuong Duong and Thanh Chuong districts. The Pu Mat NP and adjacent areas comprises of 164,805 ha. The region is intersected by steep slopes and narrow valleys with elevation ranging from $100 \mathrm{~m}$ to $1,841 \mathrm{~m}$ a.s.l. and about $90 \%$ of the territory located below 1,000 $\mathrm{m}$ a.s.l. The limited flat areas are mostly occupied by human settlements and agricultural lands. The vegetation of $\mathrm{Pu}$ Mat NP comprises mostly montane broad-leaved evergreen forests of rich and medium status, while in the lowland valleys, mixed woodbamboo forests are dominant. In adjacent areas, the vegetation is dominated by poor secondary broad-leaved evergreen forests, restored forests, mixed wood-bamboo forests, plantations of commercial trees, croplands and human settlements.

According to the recent study of Nguyen Xuan Nghia et al. (2020), the elephant population in $\mathrm{Pu}$ Mat NP region consists of 3 groups with a total of 13-14 individuals. The group in Con Cuong district has a single adult female and does not cause severe HEC in the area. The group in Tuong Duong District has 4-5 individuals, living in an area next to the Vietnam-Laos border and causing no severe HEC. The group in Anh Son district (Anh Son elephant group) is the largest (five adult females, one adult male, one sub-adult male, one juvenile male) and plays the most important role in maintaining and development of the elephant population in $\mathrm{Pu}$ Mat NP region. However, this group causes severe HEC to local communities with significant economic damage, several human death and injuries. In return, an adult elephant male was killed in retaliation in 2011. This study is focused on assessment of HEC in the Anh SonThanh Chuong area and its impact on the attitude of local communities towards the elephant conservation.

\section{MATERIALS AND METHODS}

This study was conducted in 2019-2020 with 4 field trips in March-April 2019, November 2019, February-March 2020 and April-May 2020. Each trip lasted 9-10 days. The following study methods were used:

Semi-structured interview: This method was used to collect the information on the HEC history, status, impacts and applied prevention/ mitigation measures. The interviews have been conducted in $\mathrm{Pu}$ Mat NP, the Anh Son protected forest, the Thanh Chuong protected forest, the Anh Son rubber farm, the September 12 rubber farm, the General Youth Volunteer Team II and villagers in Luc Da, Phuc Son, Thanh Duc and Thanh Son communes. Field investigation of HEC evidences was undertaken when fresh evidences were available. 
Assessment of elephant conservation attitude of local residents: The questionnaire and semi-structured interview methods were used for the assessment conducted in Luc Da, Phuc Son and Thanh Duc communes. A total of 226 local households were surveyed. The attitude of local residents to the elephant conservation is determined based on their answers to the question: "Do you want the elephants to live in your area or require the Government to translocate them to other area?".

\section{RESULTS AND DISCUSSION}

\section{HEC history and locations}

According to Nguyen Xuan Nghia et al. (2020), the current activity area of the Anh Son elephant group is about 18,000 ha covering the Anh Son protected forest, Cao Veu sector of the $\mathrm{Pu}$ Mat NP, the Thanh Chuong protected forest, the Anh Son rubber farm, September 12 rubber farm; villages Cao
Veu 1, Cao Veu 2, Cao Veu 3, Cao Veu 4, Bai $\mathrm{Da}$, Bai Lim and Kim Tien in Phuc Son commune, the third of February village in Thanh Duc commune, and Dai Son village in Thanh Son commune (Fig. 1).

HEC has been happening in Phuc Son area since 2004, but not too severe in the beginning. Since 2009, it has become more and more severe due to massive loss of natural forests in the area. Most of the Anh SonThanh Chuong area used to be covered by natural evergreen forests, but since 2009, the forests has started to be massively cleared for commercial tree plantations (Rubber, Acacia spp., Met Dendrocalamus barbatus and Bo de Styrax tonkinensis) and crop cultivation (sugar cane, bananas, etc.). However, the elephants continued to move to this area for foraging and thus raided the plantations, crops and houses, causing death and bad injuries for the local residents.

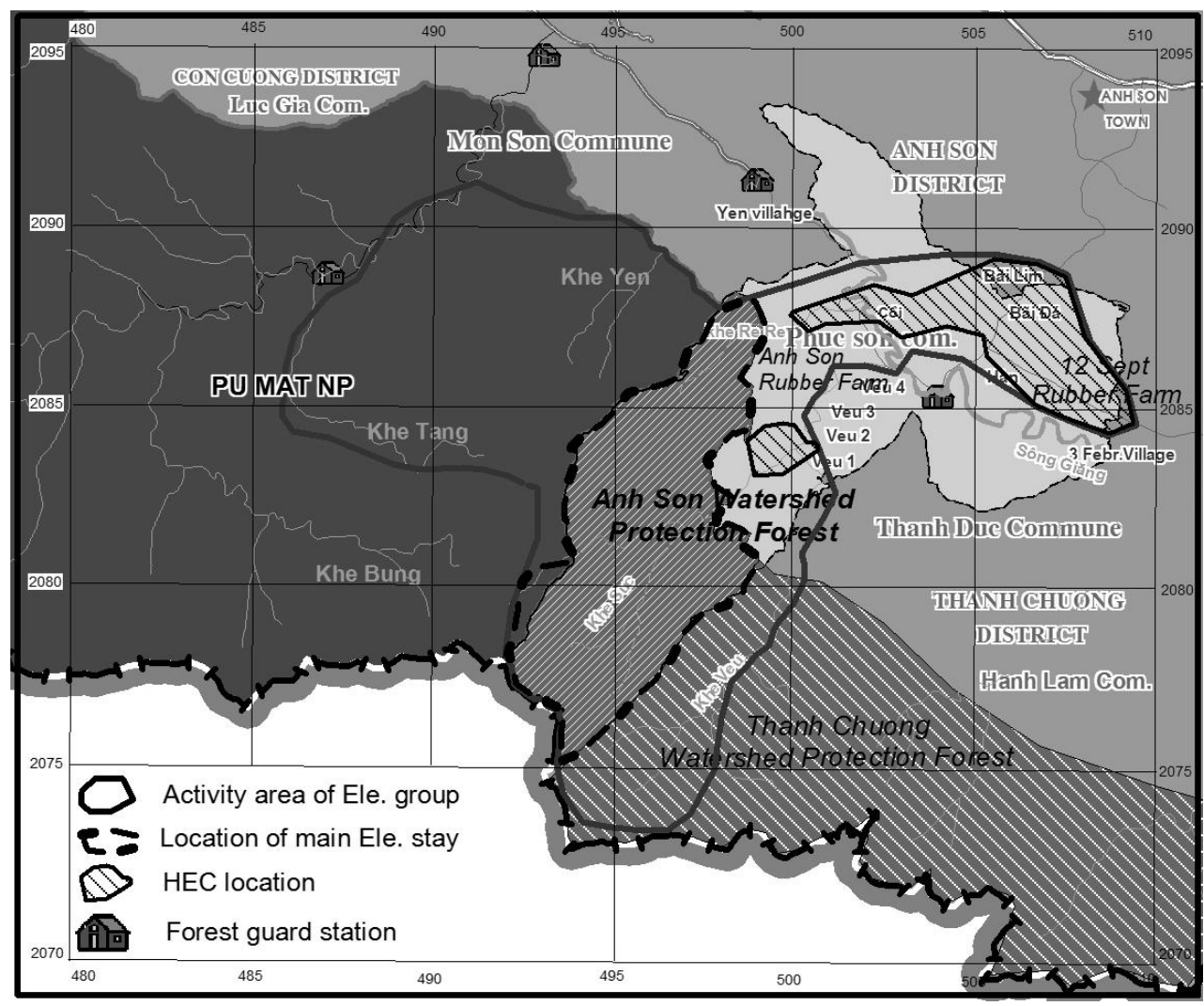

Figure 1. Current activity area of the Anh Son elephant group and HEC locations 
The elephants stay mainly in the Anh Son protected forest where secondary natural forest was the best habitat for them there. From the Anh Son protected forest, the elephants expand their activity to adjacent areas and cause HEC with local communities. The elephants move along Khe Tang, Khe Khang and Khe Yen streams in Cao Veu sector of Pu Mat NP to come into Yen village of Luc Da commune, where they sometimes raid cultivated plants, but do not cause severe HEC. In another direction, the elephants cross $\operatorname{Re} \operatorname{Re}$ stream in the Anh Son protected forest to move into territory of the Anh Son Rubber Farm, Cao Veu 4, Bai Lim, Bai Da and Kim Tien villages of Phuc Son commune, September 12 rubber farm, the General Youth Volunteer Team II, the Third of February village (Thanh Duc commune) and Dai Son village (Thanh Son commune). In this area, the elephants caused the severe HEC. On the third direction, the elephants cross Khe Suc and Khe Da Mai streams in the Anh Son protected forests to come into $\mathrm{Cao} \mathrm{Veu} 1$ village where they caused severe HEC with local villagers.

Usually, HEC occurs from August to September and from November to February of the next year when bamboo plantations have many young shoots and crops are most abundant. The elephants raid crops, destroy commercial tree plantations (Rubber, Met Dendrocalamus barbatus, Bo de Styrax tonkinensis, Acacia, Jack-fruit, etc.) and also enter houses looking for salt and stored food (rice, maize,...). As a very large animal, they often break or stomp down many trees along their routes, destroy houses and break assets in the houses. At each location, the elephants often stay 5-15 days before leaving for other locations.They hide themselves in forests at hill tops on daytime and come down to raid crops or enter to houses for food and salt from 18:00 pm to 5-6 am the next day.

\section{The direct impacts of HEC}

At present, there are no systematic records of HEC impact in the area. Some HEC incidences with significant impacts are shown in table 1.

Our study has recorded a total of 17 plant species damaged by the elephants. The most often are met, bamboo, rubber, Acacia, sugar cane, banana and maize. The damage types include eating, breaking and stomping on.

According to $\mathrm{Pu}$ Mat $\mathrm{NP}$ management board, the economic loss caused by the HEC in Anh Son area is relatively high. While there is no complete evaluation of economic loss caused by the HEC, however, high level of HEC impact can be determined from value of damages provided by the local villagers and commune authorities (Table 1).

\section{The indirect impacts of HEC}

While indirect conflicts do not directly impact livelihoods, they still have a negative effect upon people's lives. The fear of running into elephants restricts people's movements between villages and to their fields, reduces school attendance of local children, and interferes with the collection of fuel wood, thatch grass, wild fruits and other non-timber forest products which are important supplements to the subsistence or income of households. In the crop raiding season, farmers have to guard their crops and assets, leading to loss of sleep and energy, poor employment opportunities, increased exposure to infectious diseases (malaria, dengue,...) and psychological stress. In Bai Da and Bai Lim villages, when the elephants come close to village, 30-40 men gathered whole night to guard and chase out the elephants. This process lasted for 3-10 continuous days making them very tired and causing lost employment opportunities during daytime. In Boc Chau Tam settlement of Cao Veu 4 village (Phuc Son commune), there are 13 very poor families who earn their living by collecting non-timber forest products (young bamboo shoots, vegetable, fruits, medicinal plants, etc..) from natural forests close to the village. In high HEC seasons, the fear of running into elephants prevents them from entering the forests for foraging which negatively impacts their living. 
Table 1. Cases of HEC events with significant impact

\begin{tabular}{|c|c|}
\hline Time & Impact \\
\hline Nov. 2009 & $\begin{array}{l}\text { Mr. Le Van Sinh, a laborer of Anh Son Rubber Farm, was killed by elephants } \\
\text { when staying overnight in a forest shelter. }\end{array}$ \\
\hline Aug. 2011 & $\begin{array}{l}\text { Mr. Nguyen Huu Than from Bai Lim village, Phuc Son commune was badly } \\
\text { wounded by elephants when chasing the elephants out of his garden. } \\
\text { The elephants broke the house of Mr. Tran Van Duong (Bai Lim village) and } \\
\text { destroyed many trees and crops along their movement routes. Total monetary } \\
\text { value of the damage was about 100,000,000 VND (about 6,000 USD) }\end{array}$ \\
\hline Dec. 2011 & $\begin{array}{l}\text { An adult elephant male was killed near the Chau Tam settlement of Cao Veu } 4 \\
\text { village, Phuc Son Commune. The hunters took ivory off the hunted elephant. }\end{array}$ \\
\hline Dec. 2013 & $\begin{array}{l}\text { Mr. Duc from Luc Da village was killed by elephants while fishing in Da Mai } \\
\text { stream near the Cao Veu } 1 \text { village, Phuc Son commune. }\end{array}$ \\
\hline Nov. 2015 & $\begin{array}{l}\text { The elephants destroyed the sugar cane belonging to the household of Mr. Viet } \\
\text { and met plantation of the household of Mr. Dong from Cao Veu } 1 \text { village, Phuc } \\
\text { Son Commune. Total value of the damages was about 15,000,000 VND (about } \\
1,000 \text { USD) }\end{array}$ \\
\hline Dec. 2017 & $\begin{array}{l}\text { A group of } 6 \text { elephants encroached on Bai Da village (Phuc Son commune) } \\
\text { broke Acacia trees, and destroyed banana plantations and other crops of the } \\
\text { household of Mr. Pham Van Dai. The total value of the damage was about } \\
10,000,000 \text { VND (about 500.00 USD). }\end{array}$ \\
\hline Feb. 2018 & $\begin{array}{l}\text { A group of } 8 \text { elephants destroyed met, banana, sugar cane plantations and other } \\
\text { crops of three households in Cao Veu } 1 \text { village, Phuc Son commune. Total } \\
\text { value of the damage was about } 30,000,000 \text { VND (about } 1,600 \text { USD). }\end{array}$ \\
\hline Aug. 2018 & $\begin{array}{l}\text { The elephants encroached on September } 12 \text { rubber farm(in Thanh Duc } \\
\text { commune) destroying fourty rubber trees and twohouses for laborers. The total } \\
\text { value of the damage was about } 80,000,000 \text { VND (about } 4,000 \text { USD) }\end{array}$ \\
\hline Nov. 2018 & $\begin{array}{l}\text { The elephants encroached on Bai Da village, Phuc Son commune, destroyed } \\
\text { plantations of Acacia, Styrax and Dendrocalamus barbatus of Mr. Vo Van Chi. } \\
\text { The damage is valued about 35,000,000 VND (more than 1,600 USD) }\end{array}$ \\
\hline Nov. 2018 & $\begin{array}{l}\text { The elephants encroached on rubber plantation of September } 12 \text { Rrubber } \\
\text { farmand destroyed } 50 \text { rubber trees. Total value of the damage was about } \\
50,000,000 \text { VND (about } 2,500 \text { USD) }\end{array}$ \\
\hline Aug. 2019 & $\begin{array}{l}\text { The elephants came to Anh Son rubber farm and Bai Da village (Phuc Son } \\
\text { commune) where they broke fifty rubber trees, eighteenAcacia trees and } \\
\text { destroyed many other plants (banana, papaya, etc.). Total value of the damage } \\
\text { was about } 60,000,000 \text { VND (about } 2,600 \text { USD) }\end{array}$ \\
\hline $\begin{array}{l}\text { Jan-Feb. } \\
2020\end{array}$ & $\begin{array}{l}\text { The elephants came to Cao Veu } 1 \text { village (Phuc Son commune) and destroyed } \\
\text { jack-fruits, pommels, met, etc.. They also entered into the house of Mr. Dong, } \\
\text { breaking a coconut tree and kitchen assets. Total value of the damage is about } \\
80,000,000 \text { VND (about } 3,500 \text { USD). }\end{array}$ \\
\hline
\end{tabular}

Results from interviewing 226 households in Phuc Son and Thanh Duc communes show that $29.2 \%$ (66 households) has "high fear" of encountering with elephants while "medium fear" and "low fear" were felt by $14.2 \%$ (32 households) and 56.6\% (128 households). In total, "high" and "medium fear" accounted for 43,4\%. Among 110 households who suffered economic loss by HEC, the percentages for "high fear", and "medium fear" were $72.7 \%$ 
(80 households), 6.3\% (seven households) respectively, indicating high indirect negative impact of HEC in Anh Son area.

\section{Reasons of the HEC increase}

Our study reveals following causes of HEC in the Anh Son-Thanh Chuong area:

1) Significant decrease and degradation of elephant habitat: Before 2009, almost entire area of the Anh Son rubber farm and September12 rubber farm was covered by natural evergreen forest and was the suitable habitat of the $\mathrm{Pu}$ Mat elephant population. Since 2009, the natural forest have started to be massively destroyed and now almost all natural forests have been cleared and replaced by rubber and other commercial tree plantations, not suitable for the elephants. According to report of $\mathrm{Pu}$ Mat NP Management Board, before 2010, Phuc Son commune had about 43,000 ha of natural forests as habitat for the elephants. However, from 2010 to 2018, about 12,000 ha of natural forests had been converted into rubber plantations, leading to a significant decrease of food resources and movement space for the elephants. The current activity area of the elephants is about 18,000 ha of which only11,300 ha is natural forest (Nguyen Xuan Nghia et al., 2020).

2) Excessive human disturbance of the elephant habitat: The elephant habitat in Anh Son-Thanh Chuong area is heavily disturbed by activities of local residents. The residents of Phuc Son and adjacent communes often encroach into natural forests (the elephant habitat) for harvesting non-timber forest products (fuel wood, bamboo, rattan, medicinal plants etc..), fishing and hunting/trapping wild animals. They also make cropfields in some places. These activities not only caused significant disturbances to the elephants and but also made them more aggressive to people.

3) Local land-use is improper for HEC prevention: Local villagers built their houses and crop fields very close to or even within the natural forest habitat of the elephants.The seasonal movement of the elephants outside natural forests is also disturbed by the existence of many human settlements, crop fields and plantations. In addition, most crops and commercial tree plantations in the area (rice, manioc, maize, sugar cane, banana, papaya, bamboo, other fruit-bearing trees) are very attractive to the elephants.

4) Poor HEC management system: Local communities have very little knowledge and financial capacity to apply effective HEC prevention and mitigation measures. The households in Cao Veu 1 village (Phuc Son commune) usually turn on electric lamps hanging around their house to prevent the elephants from coming close. When elephants approach the house, they try to chase the elephants away by shouting loudly, making fire-spots, burning old rubber tires for unpleasant odor, making loud noises by beating metal tools, burning bamboo stems for explosion, etc. These methods have low success because the elephants rapidly get used to them. In Bai Da, Bai Lim villages, when the elephants encroach their village, 30-40 men gathered to protect the houses and fields. They use the same simple tools like in Cao Veu 1 village. However, the elephants only temporarily leave the fields/ houses, moving to nearby hills and returning back shortly after the chasing activities stopped.

In 2015, Pu Mat NP constructed a $5 \mathrm{~km}$ long concrete trench along hill slope in Phuc Son commune to block the elephants entering into the villages. However, the elephants used new routes to the villages (Cao Veu 1, Bai Lim, Bai Da and Kim Tien villages in Phuc Son commune and the village 3-4 in Thanh Duc commune) and continued to cause the severe HEC. In 2018, a "Rapid Response Team" consisting of 10 local residents have been established by Pu Mat NP to help local communities on the HEC prevention/ mitigation. However, due to lack of proper technical training and limited operational funds, the support provided by the "HEC Response Team" to the local communities is very limited.

There is a lack of many important community-based HEC mitigating 
interventions such as elephant monitoring for timely warming elephant encroachment, financial support for local communities to apply more effective HEC preventive/ mitigation measures, development of elephant-friendly livelihood projects, elephant-friendly land-use planning,...

\section{Attitude of local residents for the elephant conservation}

Local communities are very poor and the HEC causes significant economic impacts on their livelihood, threatens their lives and induces psychological stress on them. This reduces the support of local residents for the elephant conservation purposes. Results of assessment of the elephant conservation attitude are shown in Fig. 2.

Out of 110 households who suffered direct economic loss by HEC, only 24 households (21.82\%) are "supporting", the rest are "notsupporting" elephant conservation purposes. Meanwhile, all 116 (100\%) households without direct economic loss by HEC are "supporting". Out of total 226 surveyed households, 141 households $(62.39 \%)$ are "supporting" and 86 households (38.05\%) are "not-supporting". These data clearly indicate the significant decrease of support for the elephant conservation of local community in the area. Regarding the reasons of the high percentages of households agreeing with "because elephants are endangered species and being protected by governmental laws" $(100 \%)$ and "because elephants are governmental assets" $(46.8 \%, 66 / 141)$ indicate that the education on wildlife conservation law conducted by $\mathrm{Pu}$ Mat NP has achieved good results. However, only $23.4 \%$ of households replying "because elephants have been lived here for long time as a close friend of people" is lower then we expected. This is possibly because the conservation education so far has focused mostly on laws, neglecting the socio-cultural aspect of elephant conservation, and also because of the high negative impacts of the HEC on the livelihood of people. The fact that only 2 of 141 households (1.4\%) choosing "because elephants can help local economic development" reflects the real situation that no livelihood development measures associated with the elephant conservation have been initiated in the area.

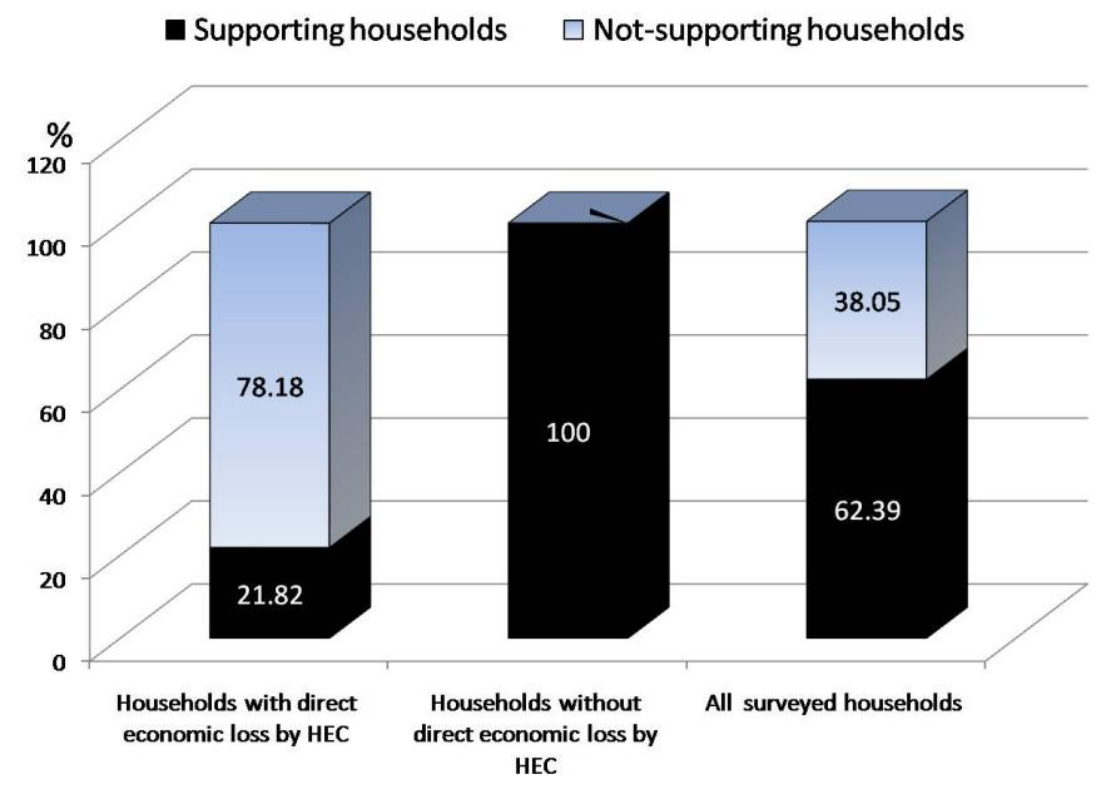

Figure 2. Diagram showing percentage of households "supporting" and "not-supporting" the elephant conservation in their area 
Regarding the attitude of local communities towards protection of remaining natural forest in the area, out of 226 interviewed households, $219 \quad$ (96.9\%) households support protection of remaining natural forests. Only 7 households request local authority to share some part of the natural forest with them for growing crops. These households lack land for crop cultivation and are very poor. Out of 219 households supporting protection of the natural forests, the replies chosen were "because of environment values: water source regulation,..." (87.2\%), "because it is essential habitat for the elephants" $(51.6 \%)$, "because the natural forests are protected by Government" (15.1\%), and "because the forests supply non-timber products for villages" (14.2\%). These data indicate that local communities understand well the environmental and economic values of the natural forest. However, their understanding ofthe importance of the natural forests for elephant conservation is still low.

\section{CONCLUSION}

Out of three elephant groups currently habiting $\mathrm{Pu}$ Mat NP region, only group in Anh Son District causes severe HEC, where they raid crop, destroy commercial tree plantations, houses and assets. The HEC causes relatively high economic damages for local villagers and rubber farms, threatens human life and induces human psychological pressure. Because of HEC, the support of local residents for elephant conservation has been significantly reduced. Key reasons of the HEC are as follows: the natural forest has been significantly reduced and degraded due to its massive conversion into commercial tree plantations and agricultural lands; the elephant habitat is excessively disturbed by non-timber forest product harvesting, wildlife hunting/trapping, and agricultural cultivation of local residents; the local land-use is improper (in term of HEC mitigation) with human settlements and crop fields located very close to or within the elephant habitat and widespread farming of elephant attractive plants. The current HEC management system is still very poor and lack of interventions with active participation of local communities.

Acknowledgements: This study was funded by the International Elephant Foundation (IEF) through the grant "Community-based human elephant conflict mitigation in $\mathrm{Pu}$ Mat National Park, Vietnam" and Vietnam Academy of Science and Technology (VAST). The authors would like to express sincere thanks to the IEF and VAST for the invaluable supports and to management boards of Pu Mat NP, the Anh Son protected forest, the Thanh Chuong protected forest and local authorities for the kind support of our study. Our sincere thanks are also to all staff of these organizations and local residents who have offered us invaluable help during our field study.

\section{REFERENCES}

Desai A. A., Riddle H. S., 2015. Humanelephant conflict in Asia. 92 pp.

Decision no. 763/QD-TTg, dated 21 May 2013 of the Prime Minister, approving the "General plan of elephant conservation in Vietnam, period 2013-2020”. (in Vietnamese).

Fernando P., Kumar M. A., Williams A. C., Wikramanayake E., Aziz T.,SinghS. M., 2008. Review of human-elephant conflict mitigation measures practiced in South Asia. AREAS technical support document submitted to World Bank. Published by WWF. 50 pp.

IEF, 2017. Asian elephant range state meeting: A final report. Jakarta, Indonesia, April 18-20, 2017. International Elephant Foundation and IUCN/SSC Asian Elephant Specialist Group. 68 pp.

NPPC and WWF-Bhutan, 2016. Human wildlife conflict strategy: Nine gewogs of Bhutan, National Plant Protection Centre (NPPC), Thimphu, Bhutan and WWF Bhutan,Thimphu. 80 pp.

Nguyen Xuan Dang, 2015. Overall evaluation of the wild Asian elephant population Elephas maximus in Vietnam. A technical 
report submitted to WWF-Vietnam, Hanoi, Vietnam. 59 pp.

Nguyen Xuan Nghia, Nguyen Tien Dat, Nguyen Xuan Dang, Tran Xuan Cuong, Vo Cong Anh Tuan, 2020. Current status of Asian elephant population, Elephas maximus, in Pu Mat National Park region, Nghe An Province. Academia Journal of Biology,42(2):55-64. https://doi.org/ 10.15625/0866-7160/v42n2.14668

Phub D., T. Ugyen, R. Pema, KarmaC.,Singye W., 2017. Human-elephant conflict management report. Department of
Forests and Park Services, Ministry of Agriculture and Forests, Bhutan.

Vietnam Forestry Department, 2018. Report on evaluation of results of implementing the "General plan of elephant conservation in Vietnam, period 2013-2020" approved by Decision no. 763/QD-Ttg, dated 21 May 2014 of the Prime-Minister. Ha Noi, 20 pp. (in Vietnamese).

WWF, 2015. Safe Systems: Revolutionizing Human Wildlife Conflict. WWF Tigers Alive Initiative, 4 pp. 